\title{
Práticas operacionais e de empreendimentos - Análise crítica dos instrumentos legais do ministério da agricultura, pecuária e abastecimento (MAPA) para uso agrícola do lodo de esgoto Critical analysis of the legal instruments of the Ministry of Agriculture, Livestock and Food Supply - MAPA for agricultural use of sewage sludge

\author{
- Data de entrada: \\ 22/08/2014 \\ - Data de aprovação: \\ 03/03/2016
}

\section{Resumo}

O uso agrícola de lodo de esgoto é possível através de duas abordagens distintas: como resíduo ou como produto. A abordagem "resíduo" deve seguir as diretrizes do Ministério do Meio Ambiente. Já a abordagem "produto" deve seguir as diretrizes do Ministério da Agricultura, Pecuária e Abastecimento - MAPA.

Este artigo apresenta uma análise crítica dos instrumentos legais do MAPA, que apesar de serem bastante restritivos quanto aos padrões de qualidade do produto derivado contendo lodo de esgoto, apresentam lacunas que, se não forem preenchidas, podem colocar em risco tanto a segurança agrícola quanto a segurança sanitária e ambiental.

Como a abordagem de uso agrícola do lodo como um resíduo urbano estabelecido pela Resolução CONAMA - RC n 375/2006 apresenta uma série de empecilhos de ordem prática, como um número excessivo de análises laboratoriais, monitoramento das áreas de cultivo e outras dificuldades de ordem logística, a abordagem de produto vem ganhando destaque em seu uso, especialmente no Estado de São Paulo.

Assim, para viabilizar o uso agrícola via produto, buscou-se complementar os textos do MAPA com os requisitos de higienização e redução da atratividade a vetores dos textos da agência americana de proteção ambiental - EPA, de modo que o lodo tratado seja utilizado como matéria-prima na produção de fertilizante orgânico ou, dependendo de suas características, diretamente como fertilizante, sem comprometer a segurança ambiental e agrícola.

Palavras-chave: resíduo, biossólido, uso benéfico, padrões de qualidade, lodo de ETE, uso agrícola, legislação ambiental.

Bruno Sidnei da Silva - Engenheiro Sanitarista e Ambiental graduado pela Universidade Federal de Santa Catarina. Engenheiro do Departamento de Pesquisa, Desenvolvimento Tecnológico e Inovação da Companhia de Saneamento Básico do Estado de São Paulo - SABESP. Marcelo Kenji Miki - Engenheiro Civil, Mestre em Engenharia Hidráulica e Saneamento pela Escola Politécnica da Universidade de São Paulo, Gerente do Departamento de Projetos de Pesquisa da Superintendência de Pesquisa, Desenvolvimento e Inovação da Companhia de Saneamento Básico do Estado de São Paulo - SABESP.

Endereço para correspondência: Rua Costa Carvalho, n 300 - Pinheiros - São Paulo - SP - CEP: 05429-900 - Brasil. Tel: +55 (11) $3388-9751$

- Fax: +55 (11) 3388-8695 - e-mail: bsidneiasabesp.com.br. 


\section{Abstract}

The agricultural use of sewage sludge is possible through two distinct approaches: as waste or as an agricultural product. The residue approach should follow the guidelines of the Ministry of Environment. But if the approach adopted for the agricultural product, should follow the guidelines of the Ministry of Agriculture, Livestock and Supply - MAPA. This article presents a critical analysis of the legal MAPA instruments, which despite being quite restrictive as to the quality standards of the derivative product containing sewage sludge, has gaps that are not met can endanger both agricultural security as health security and environmental.

As the sludge for agricultural use approach as an urban waste established by CONAMA Resolution - RC $n^{\circ}$ 375/2006 has a number of practical obstacles, such as an excessive number of laboratory tests, monitoring of croplands and other logistical problems, the product approach has been gaining momentum in its use, especially in São Paulo State.

Thus, to enable agricultural use via product, it sought to complement the MAPA texts with hygiene requirements and reduce the attractiveness of the vectors of texts of American Agency Environmental Protection -EPA, so that the treated sludge is used as a feedstock in the organic fertilizer production or, depending on their characteristics, directly as fertilizer, without compromising environmental safety and agricultural.

Keywords: waste, biosolids, beneficial use, agricultural use, quality standards, wastewater treatment plant sludge, environmental regulation.

\section{INTRODUÇÃO}

A crescente preocupação ambiental e o investimento crescente em saneamento básico vêm aumentando a preocupação com o destino final do lodo de esgoto gerado nas estações de tratamento. Uma das alternativas de disposição final mais conhecida no meio técnico é o aterro sanitário. Frente à disposição final, alternativas de reaproveitamento deste material vêm sendo estudadas e empregadas por diversas companhias de saneamento no Brasil e no mundo, devido ao seu potencial de fornecer nutrientes para as plantas, poder calorífico, capacidade de retenção de água, entre outras características. $\mathrm{O}$ aproveitamento destas características do lodo de esgoto pode ser denominado de uso benéfico. As alternativas de uso benéfico envolvem a aplicação direta em culturas agrícolas, a incorporação na produção de insumos da construção civil, etc.

Dentre as opções citadas no parágrafo anterior, o uso benéfico do lodo de ETE como insumo ou produto agrícola parece ser uma alternativa ade- quada do ponto de vista ambiental, já que cerca de $60 \%$ do montante de nutrientes inorgânicos presentes em alimentos são despejados nos esgotos, após tomarem parte do metabolismo humano (Kvarnstrom \& Nilsson, 1999 apud Correa, 2001). De acordo com Sampaio (2013), estima-se que "a quantidade de lodo de ETE utilizada no Brasil para o fim agrícola é da ordem de 21.000 toneladas (base seca)/ano, sendo produzido em quase sua totalidade em estações que utilizam processos de tratamento biológicos aeróbios (lodos ativados convencionais ou aeração prolongada e lagoas aeradas). Apesar de as inúmeras vantagens apresentadas por essa prática em relação às demais formas de destinação final, seu emprego em território nacional pode ser considerado incipiente quando comparado com países norte-americanos e europeus".

A aplicação direta de lodo de esgoto em culturas agrícolas é regulamentada pelo Ministério do Meio Ambiente, através do seu órgão consultivo e deliberativo - Conselho Nacional do Meio Am- 
biente - CONAMA que regulamentou a prática em território nacional através da Resolução CONAMA - RC n 375/2006. Para o CONAMA, lodo de esgoto é conceituado como um resíduo gerado nos processos de tratamento de esgoto sanitário com potencial de uso agrícola.

No Estado de São Paulo, desde a publicação no ano de 1999, pela Companhia Ambiental do Estado de São Paulo - CETESB, da Norma P4230, nunca se conseguiu uma única licença ambiental para o uso agrícola de lodo de ETE, apesar dos vários esforços empreendidos. Desde então, para viabilizar o uso agrícola do lodo, sem desperdícios de tempo e dinheiro, as empresas paulistas operadoras de saneamento têm evitado percorrer este caminho burocrático.

Outra opção para tornar o uso agrícola do lodo de esgoto possível na prática é através do atendimento aos dispositivos estabelecidos pelo $\mathrm{Mi}$ nistério da Agricultura, Pecuária e Abastecimento - MAPA. Esta trajetória é realizada através do beneficiamento do lodo até que ele adquira qualidade para ser utilizado diretamente ou como matéria-prima na produção de fertilizante orgânico, fertilizante organomineral ou como corretivo (condicionador de solo) classe D. Fertilizante orgânico é um produto de natureza fundamentalmente orgânica, obtido por processo físico, químico, físico-químico ou bioquímico, natural ou controlado, a partir de matérias-primas de origem industrial, urbana ou rural, vegetal ou animal, enriquecido ou não de nutrientes minerais. Fertilizante organomineral é a mistura física ou combinação de fertilizantes minerais e orgânicos. Já condicionador de solo é o produto que promove a melhoria das propriedades físicas, físico-químicas ou a atividade biológica do solo. Tanto a produção quanto o comércio destes produtos para aplicação em culturas agrícolas são atividades controladas pelo MAPA. Nota-se a mudança de enfoque para o lodo de esgoto, de resíduo (CONAMA) para matéria-prima ou produto agrícola (MAPA).
O uso benéfico do lodo de ETE como produto agrícola em vez de resíduo acarreta uma série de mudanças na forma de gerenciar o lodo gerado nas estações. O gerenciamento da fase sólida da estação passa a ganhar uma relevância significativa, já que o material gerado deverá apresentar padrão de qualidade bastante rígido e constante. Para atingir este objetivo, o estabelecimento deverá manter um sistema de controle da qualidade que ateste a conformidade das características físicas, microbiológicas e nutricionais do produto gerado com os padrões de qualidade estabelecidos nos instrumentos legais do MAPA.

A percepção atual de quem percorre a trajetória legal estabelecida pelo MAPA para uso agrícola é de que seus padrões de qualidade são suficientes para preservação do meio ambiente e da saúde pública, já que muitas das exigências são muito mais restritivas que a própria RC n 375/2006. No entanto, ao longo do texto discutiremos uma série de lacunas dos instrumentos do MAPA que podem passar despercebidas e que merecem ser destacadas.

Assim, o objetivo deste artigo é analisar os instrumentos legais envolvidos na produção de produtos agrícolas contendo lodo de esgoto em sua composição e propor recomendações para as alternativas de tratamento do lodo visando à produção de um produto agrícola com padrão de qualidade e repetitividade exigidos pelo MAPA, de modo que a produtividade agrícola seja assegurada sem pôr em risco a segurança sanitária e ambiental advinda do seu uso.

\section{BENEFÍCIOS DA ABORDAGEM DE PRODUTO FRENTE À ABORDAGEM DE RESÍDUO}

A principal vantagem da abordagem de produto frente à abordagem de resíduo é que as restrições ambientais estabelecidas na $\mathrm{RC}$ n० $375 / 2006$ para aplicação de lodo de ETE no solo, tais como o monitoramento de metais pesados na área de cultivo, não mais se aplicariam, passando a se seguir 
exclusivamente as diretrizes para uso agrícola estabelecidas nos instrumentos legais do MAPA. No Estado de São Paulo, a CETESB já reconhece que a aplicação de lodo de esgoto no solo registrado no MAPA como produto agrícola não depende de sua manifestação (São Paulo, 2010). Assim, após o processo de beneficiamento do lodo de resíduo para produto, a aplicação do produto derivado no solo agrícola deve se submeter apenas aos instrumentos legais do MAPA, bem como todo trâmite burocrático se restringirá somente a este órgão.

Outra vantagem do uso benéfico do lodo de ETE como produto está relacionada ao seu ciclo de vida, cuja responsabilidade é compartilhada entre o produtor, comerciante e o agricultor, ou seja, o estabelecimento produtor fica responsável pela qualidade do produto, o comerciante (quando houver), pela correta armazenagem, proteção e guarda destes produtos, e o agricultor, pela aplicação no solo, respeitando as taxas de aplicação com base na concentração de nutrientes e de acordo com a recomendação e responsabilidade de um profissional tecnicamente habilitado. $\mathrm{Na}$ abordagem de resíduo, o gerador de lodo de esgoto é responsável por toda a cadeia, desde a produção até períodos posteriores à disposição no solo, gerando para o estabelecimento a necessidade de empregar um sistema de controle e rastreamento tão rigoroso que dificulta e iniba a prática, principalmente para as ETEs de pequeno porte.

Ainda com relação ao ciclo de vida do produto agrícola, seu transporte não apresenta vantagem em relação à abordagem de resíduo. Conforme o artigo 48 do Decreto Federal no 4954/2004, o transporte de fertilizantes, corretivos, inoculantes ou biofertilizantes em território nacional deve ser submetido aos regulamentos para transporte de produtos perigosos. $\mathrm{E}$, de acordo com a legislação específica do setor de transporte de produtos perigosos - Resolução nº 420/2004 da Agência Nacional de Transportes Terrestres, o estabelecimento produtor é corresponsável pelo transporte deste material até o usuário final ou estabelecimento comercial.

Por focar o controle de qualidade dos produtos para uso agrícola no processo produtivo, o MAPA torna possível o emprego de parâmetros de controle operacional, o que não é possível na abordagem de resíduo da $\mathrm{RC} \mathrm{n}^{\circ}$ 375/2006, que determina a comprovação analítica de todo lote de lodo de esgoto disponibilizado para uso. Após o registro como produto agrícola, a qualidade analítica do produto será averiguada pelo MAPA através de fiscalizações periódicas, que abrangem desde as instalações produtivas até o sistema de controle de qualidade do estabelecimento.

\section{AVALIAÇÃO DOS INSTRUMENTOS LEGAIS DO MAPA}

Os instrumentos legais do MAPA são bastante rígidos com relação aos padrões de qualidade para produto, tanto para os parâmetros de interesse agronômico, quanto para os limites de patógenos e metais pesados (conceituados pelos agrônomos como as substâncias que podem causar fitotoxicidade às culturas agrícolas ou entrar na cadeia alimentar). Portanto, esta alternativa levará as companhias a adotar processos de tratamento e controle de produtos gerados tão ou mais rigorosos do que se a abordagem do lodo gerado fosse de resíduo.

Antes de comentarmos os parâmetros referentes a contaminantes, no que tange às concentrações máximas de patógenos e metais pesados, apresentamos uma rápida abordagem sobre os parâmetros de interesse agronômico estabelecidos pelo MAPA para registro do produto como fertilizante orgânico composto ou condicionador de solo classe D. Como a composição do fertilizante organomineral classe $D$ envolve a mistura física ou combinação de fertilizantes minerais e orgânicos, não será considerada essa alternativa de produto na discussão deste artigo, já que não será, muito provavelmente, a opção escolhida pe- 
las companhias operadoras de ETE, devido à necessidade de aporte de matérias-primas minerais ao lodo, o que levaria a significativo aumento de custos na produção do fertilizante. Contudo, caso essa seja a opção escolhida pelo estabelecimento, é preciso atender aos requisitos agronômicos definidos na legislação tanto para fertilizante orgânico quanto para fertilizante mineral. Quanto aos contaminantes, deverá ser seguida a referência mais restritiva quando houver conflito de concentração para um mesmo parâmetro.

A Tabela 1 apresenta as concentrações estabelecidas pelo MAPA para registro de fertilizante orgânico composto classe $\mathrm{D}$ e condicionador de solo classe D.

Tabela 1 - Garantias e limites máximos de patógenos para fertilizantes orgânicos e condicionadores de solo classe D

\begin{tabular}{|c|c|c|}
\hline \multirow{2}{*}{ Garantia } & Fertilizante Orgânico Classe D (Brasil, 2009) & Condicionador de Solo Classe D (Brasil, 2006b) \\
\hline & Valor & Valor \\
\hline Umidade máxima (\%) & 70 (estado sólido) & 70 (estado sólido) \\
\hline Nitrogênio Total (mín) (\%) & 0,5 & 0,5 \\
\hline Carbono Orgânico (mín) (\%) & 3 (estado fluido), 15 (estado sólido) & 15 (estado sólido) \\
\hline $\begin{array}{l}\text { CTC - Capacidade de Troca Catiônica } \\
\text { (mín) (mmol c/kg) }\end{array}$ & Conforme Declarado & 200 \\
\hline pH mínimo & 6,0 & 6,0 \\
\hline Relação C/N (máx) & 20 & 20 \\
\hline Relação CTC / C & Conforme Declarado & Conforme Declarado \\
\hline Fósforo (Teor Total em $\mathrm{P}_{2} \mathrm{O}_{5}$ ) (\%) & Conforme Declarado & Conforme Declarado \\
\hline $\begin{array}{l}\text { Óxido de Potássio } \\
\text { (Teor Solúvel em Água) (\%) }\end{array}$ & Conforme Declarado & Conforme Declarado \\
\hline Outros Nutrientes & Conforme Declarado & Conforme Declarado \\
\hline Capacidade de Retenção de Água (mín) (\%) & - & 60 \\
\hline \multirow{2}{*}{ Limites Máximos de Patógenos } & Fertilizante Orgânico Classe D (Brasil, 2006a) & Condicionador de Solo Classe D (Brasil, 2006a) \\
\hline & Valor & Valor \\
\hline Coliformes Termotolerantes (NMP/g de MS) & 1000 & 1000 \\
\hline Ovos Viáveis de Helmintos ( $\mathrm{n}^{\circ} \mathrm{em} 4 \mathrm{~g}$ de ST) & 1,00 & 1,00 \\
\hline Salmonellasp. & Ausência em 10 gramas de MS & Ausência em 10 gramas de MS \\
\hline
\end{tabular}

Fonte: Brasil, 2006a; Brasil, 2006b e Brasil, 2009.

Observa-se na Tabela 1 que as garantias para condicionadores de solo classe D são as mesmas garantias para fertilizantes orgânicos compostos classe $\mathrm{D}$, acrescidas de dois parâmetros: $\mathrm{Ca}$ pacidade de Retenção de Água e Capacidade de Troca Catiônica. Na verdade, as demais classes de condicionadores de solo apresentadas em Brasil (2006b) apresentam como garantias mínimas apenas esses dois parâmetros citados. Contudo, o MAPA condicionou o registro dos condicionadores de solo Classe $D$ ao atendimento das mesmas garantias dos fertilizantes orgânicos compostos dessa mesma classe, tornando o registro do produto como condicionador classe $\mathrm{D}$ mais restritivo do que como fertilizante.
Outra observação da tabela anterior refere-se ao teor mínimo de nitrogênio e carbono orgânico. Esses elementos, mesmo que atendidos individualmente, não garantem a conformidade do material para o registro como fertilizante orgânico, devido ao padrão máximo exigido para a relação $\mathrm{C} / \mathrm{N}$. Ou seja, supondo certa massa de fertilizante orgânico contendo $0,5 \%$ em peso seco de nitrogênio total, e $15 \%$ em peso seco de carbono orgânico, o material atenderia ao padrão mínimo exigido para estes dois elementos, contudo, sua relação $\mathrm{C} / \mathrm{N}$ seria igual a 30, bastante superior ao limite máximo de 20 estabelecido pelo MAPA. Em suma, mesmo que um fertilizante orgânico classe $D$ atenda aos padrões mínimos de nitrogênio e carbono orgâni- 
co, deve-se balancear na sua produção um desses elementos, de modo que a relação $\mathrm{C} / \mathrm{N}$ máxima seja atendida no produto.

Quanto às concentrações máximas de patógenos fixadas pelo MAPA, observa-se que são idênticas às concentrações estabelecidas na RC n 375/2006, com exceção da presença de vírus entéricos, fixada apenas na regulamentação ambiental. Inferese que o MAPA, na definição destes limites de patógenos, adotou o conceito de risco nulo, ou seja, a utilização de produto agrícola contendo lodo de esgoto apresentaria probabilidade zero de causar algum dano ambiental ou algum dano à saúde da população exposta ao produto. Para algumas situações, o MAPA também utilizou o princípio da dupla barreira, já que, além dos limites de contaminantes bastante rigorosos, estabeleceu restrições de aplicação para certas culturas agrícolas, além de ter exigido em seus instrumentos normativos o uso de equipamentos de proteção individual durante o manuseio e aplicação do produto no solo. Porém, apesar da dupla barreira imposta ao uso de produto contendo lodo de esgoto, o MAPA não indicou em seus instrumentos legais as tecnologias ou alternativas de tratamento da matéria-prima, lodo de esgoto, necessária para a obtenção de um produto com seu padrão de qualidade microbiológica, ou seja, com ausência de patógenos. Não há nenhuma menção em seus textos sobre processos de higienização do lodo e, além disso, não considera a possibilidade deste material ser "recontaminado" antes de sua aplicação no solo, caso não seja adotada alguma medida para redução da sua atratividade a vetores.

Para sanar esta lacuna e visando garantir a segurança tanto de quem produz quanto de quem utiliza um produto contendo lodo de esgoto em sua composição, entendemos que a sua produção com o padrão de qualidade microbiológica exigido pelo MAPA deverá inevitavelmente recorrer aos processos de higienização do lodo e redução da sua atratividade a vetores mencionados nos textos das instituições de proteção ambiental.

A agência ambiental norte-americana - EPA, estabelece no seu texto voltado ao uso agrícola de lodo de esgoto - 40 CFR EPA Part 503 (Estados Unidos, 1993), daqui em diante denominada simplesmente de "Norma 503", uma listagem extensiva de alternativas e processos de higienização do lodo visando obter um lodo com padrão Classe A ou Classe B.

Cabe, neste momento, esclarecer as terminologias utilizadas pelas instituições ambientais na classificação de lodo de esgoto, a fim de evitar comparações com a terminologia do MAPA.

Para a Norma 503, as classificações Lodo Classe $A$ e Lodo Classe $B$ se referem à concentração de patógenos no lodo tratado. Lodo Classe A é o lodo que foi tratado em um processo que resulta em uma concentração final de patógenos (Salmonella sp., vírus entéricos e ovos viáveis de helmintos) abaixo dos limites analíticos de detecção. Lodo Classe B é o lodo que foi tratado em um processo que resulta em uma concentração final de patógenos acima dos limites de detecção analíticos, contudo, a uma certa concentração que, associada a medidas de restrição de contato com o público e práticas de manejo, não apresenta riscos à saúde pública.

Já a classificação “Classe D” do MAPA para Fertilizante Orgânico ou Condicionador de Solo não tem qualquer relação com o processo de higienização empregado para o lodo de esgoto. Esta classificação representa uma das classificações do MAPA para fertilizantes orgânicos simples, mistos, compostos e organominerais, e para condicionadores de solo, indicando a classe do produto que em sua composição utiliza quaisquer quantidades de lodo de esgoto. 
A Figura 1 apresenta a proposta de beneficiamento do lodo de ETE visando seu registro e uso como produto agrícola.

Figura 1 - Beneficiamento do lodo de esgoto. De resíduo (CONAMA) para matéria-prima ou produto agrícola (MAPA)

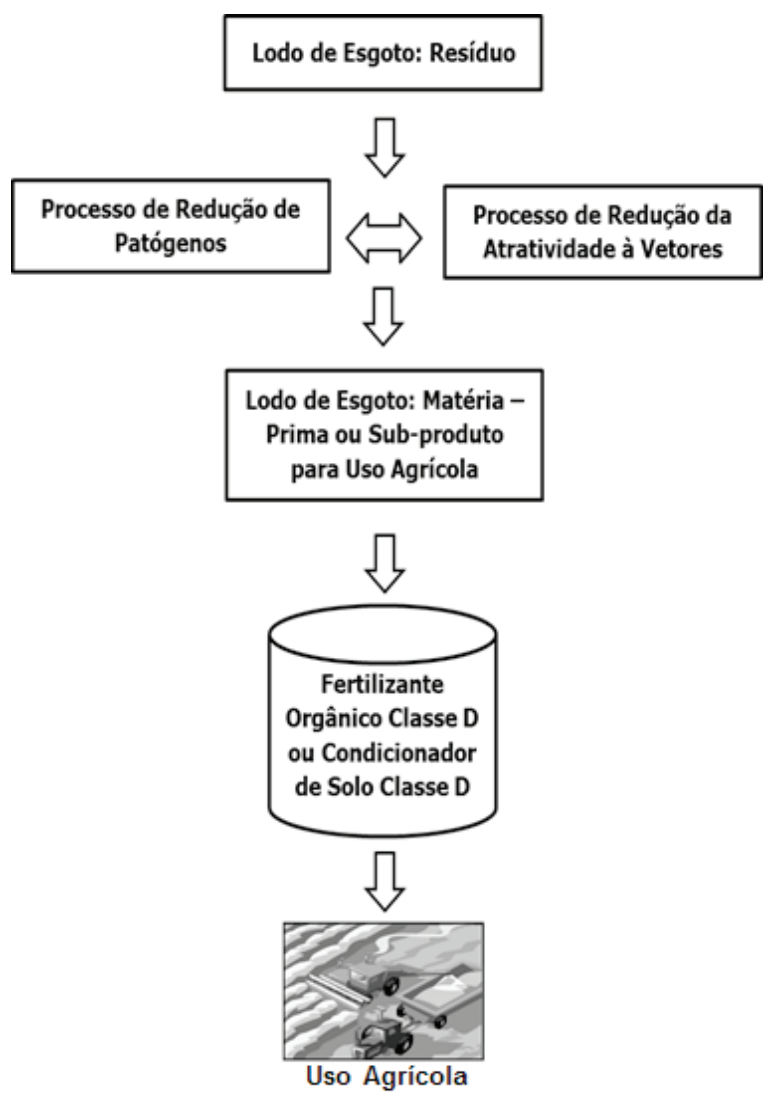

Observa-se que para o MAPA o enfoque é totalmente distinto das instituições de proteção ambiental, ou seja, não se trata da gestão e aplicação direta no solo agrícola de um resíduo gerado nas estações de tratamento de esgotos, mas de um material cuja composição o torna matéria-prima para produção de um fertilizante ou condicionador de solo, cujos padrões de contaminantes (metais pesados) e organismos patogênicos são estabelecidos em regulamentos próprios.

\section{DENSIDADE DE PATÓGENOS}

O MAPA, através da Instrução Normativa - IN MAPA n 27/2006 (Brasil, 2006a), apresenta os requisitos de patógenos para fertilizantes orgânicos e condicionadores de solo Classe D. Apesar de serem apenas organismos indicadores de patogenicidade, os coliformes termotolerantes estão agrupados neste artigo na categoria de patógenos, para simplificar as discussões e comparações entre os diversos instrumentos legais citados neste artigo. As densidades máximas de patógenos regulamentadas pelo MAPA são as apresentadas a seguir:

- Coliformes Termotolerantes $\leq 1000$ NMP/g de MS;

- Ovos Viáveis de Helmintos $\leq 1$ em 4g ST;

- Salmonella sp.: ausência em $10 \mathrm{~g}$ de matéria seca.

Percebe-se uma falta de padronização da terminologia nas unidades de medida nesses requisitos do MAPA, já que para designar a base seca do lodo, não adotou as mesmas palavras ou siglas.

Já a RC n³75/2006 estabelece para Lodo Classe A os seguintes requisitos:

- Coliformes Termotolerantes < 1000 NMP/g de ST;

- Ovos Viáveis de Helmintos <0,25 em g ST;

- Salmonella sp.: ausência em 10 g de matéria seca;

- Vírus $<0,25$ UFP/g ST

E importante destacar que a Norma 503 para Lodo Classe A estabelece como requisitos (com destaque para ou e não e):

- Coliformes Termotolerantes < 1000 NMP / g de Sólidos Totais ou;

- Salmonella sp. < 3 NMP / 4 g de Sólidos Totais.

De acordo com Bastos (2013), nos EUA o padrão de coliformes termotolerantes é assumido como indicador da ausência de Salmonella sp. Assim, 
como controle de qualidade do biossólido (termo utilizado para ressaltar os aspectos benéficos do lodo de esgoto, valorizando a utilização produtiva em comparação com a mera disposição final improdutiva em aterros sanitários, disposição superficial no solo ou incineração), a norma dos EUA exige $o$ atendimento das concentrações máximas de coliformes termotolerantes "ou" de Salmonella sp. Biossólidos Classe A também devem estar livres de vírus entéricos e ovos (viáveis) de helmintos (abaixo dos limites de detecção). Entretanto, na Norma 503 essa condição pode ser demonstrada pelo monitoramento desses patógenos ou de variáveis de controle operacional dos processos de tratamento do lodo. Infere-se, portanto, que o padrão de coliformes termotolerantes não é assumido como indicador confiável da ausência de vírus entéricos e de ovos de helmintos, mas que as variáveis operacionais se prestam, sim, ao papel de indicadores da eficiência do tratamento e substituem o controle por meio do monitoramento de patógenos.

Ainda de acordo com Bastos (2013), "os parâmetros microbiológicos da Norma 503 para biossólidos Classe A têm como referência os limites de detecção dos métodos disponíveis à época (Estados Unidos, 1993) para a pesquisa de patógenos, os quais, por definição (ou por razões logísticas), são baseados em um dado tamanho amostral (em termos de massa). Essas questões explicam os limites adotados, aparentemente estranhos, como < 3 Salmonella sp. (NMP) /4 g ST, < 1 enterovírus (UFP) /4 g ST e < 1 ovo de helminto/4 g ST. Entretanto, a ausência de microrganismos numa pequena quantidade de material não assegura sua ausência em amostras maiores provenientes da mesma fonte. Assim, poderia ser especulado (somente especulado) que essa seria a razão do limite brasileiro para Salmonella sp. ser especificado com base na ausência em $10 \mathrm{~g}$, talvez objetivando um padrão mais rigoroso ou mais seguro".
Os requisitos de densidade de patógenos estabelecidos pelo MAPA são mais rigorosos que os da Norma 503, e similar ao da RC n³ 375/2006, com exceção do padrão de vírus entéricos. Portanto, estes requisitos de patógenos do MAPA são mais restritivos que o padrão de Classe $A$ da Norma 503.

Desde 2011, a RC n 375/2006 baniu o uso do lodo Classe $\mathrm{B}$ conforme estabelecido no parágrafo $1^{\circ}$ do seu Artigo 11. Apesar da realização de estudos no Brasil questionando o rigor excessivo desta resolução em relação ao Lodo Classe B, não houve na prática ações que levassem a uma revisão dessa resolução. Portanto, caso seja adotada a abordagem de resíduo junto ao órgão ambiental, atualmente somente é possível o uso agrícola como Lodo Classe A.

Para estabelecer um ponto de partida do uso agrícola de um insumo agrícola contendo lodo de ETE, pode-se inicialmente seguir de forma voluntária as diretrizes preconizadas para a produção de lodo Classe A da Norma 503, bem como seus critérios para redução da atratividade a vetores. Obedecidas estas diretrizes, faz-se a caracterização completa estabelecida pelo MAPA (coliformes termotolerantes, ovos de helmintos e Salmonella sp.) e checa-se o atendimento aos parâmetros para um determinado lote. Como há um rigor maior na densidade de patógenos no MAPA, deve-se checar se os processos de higienização do lodo da Norma 503 atendem aos seus requisitos e, caso contrário, deve-se alterar os parâmetros operacionais dos processos até que esses requisitos sejam atendidos.

Para que processos de higienização sejam reconhecidos como processos de produção de Lodo Classe A nos EUA, necessitam atender certos critérios, de acordo com a alternativa empregada no processo de higienização. Os critérios estão apresentados na Tabela 2, de acordo com seis alternativas de higienização apresentadas no texto da Norma 503. 
Tabela 2 - Alternativas de higienização para obtenção de Lodo Classe A. Fonte: Estados Unidos, 1994a

\begin{tabular}{|c|c|c|c|c|}
\hline \multirow{2}{*}{ Alternativas } & \multicolumn{4}{|c|}{ Requisitos } \\
\hline & Regime & Aplicação & Requisitos & Relação Tempo x Temperatura \\
\hline \multirow{5}{*}{$\begin{array}{l}\text { Alternativa 1: } \\
\text { Lodo Tratado Em Um } \\
\text { de Quatro Regimes } \\
\text { Possíveis de Tempo e } \\
\text { Temperatura. }\end{array}$} & A & $\begin{array}{l}\text { Lodo com TS > }=7 \% \text { (exceto } \\
\text { aqueles atendidos pelo Regime B) }\end{array}$ & $\begin{array}{l}\text { A temperatura do lodo deve ser mantida } \\
\text { igual ou acima de } 50^{\circ} \mathrm{C} \text { por no mínimo } 20 \\
\text { minutos. }\end{array}$ & $D=\frac{131700000}{10^{0,14 t}}$ \\
\hline & B & $\begin{array}{l}\text { Lodo com TS >= } 7 \% \text { na forma de } \\
\text { pequenas partículas aquecido } \\
\text { através do contato entre gases } \\
\text { ou líquidos imiscíveis aquecidos. }\end{array}$ & $\begin{array}{l}\text { A temperatura do lodo deve ser mantida } \\
\text { igual ou acima de } 50^{\circ} \mathrm{C} \text { por no mínimo } 15 \\
\text { segundos. }\end{array}$ & $D=\frac{131700000}{10^{0,14 t}}$ \\
\hline & C & Lodo com TS $<7 \%$ & $\begin{array}{l}\text { Aquecido de, no mínimo, } 15 \text { segundos até } \\
30 \text { minutos. }\end{array}$ & $D=\frac{131700000}{10^{0,14 t}}$ \\
\hline & D & Lodo com TS $<7 \%$ & $\begin{array}{l}\text { A temperatura do lodo deve ser mantida } \\
\text { igual ou acima de } 50^{\circ} \mathrm{C} \text { por no mínimo } 30 \\
\text { minutos de tempo de contato. }\end{array}$ & $D=\frac{50070000}{10^{0,14 t}}$ \\
\hline & \multicolumn{4}{|c|}{$\begin{array}{l}\text { Atendimento dos Requisitos de Coliformes Termotolerantes ou Salmonella sp. (Ver Tabela 4) para todos os regimes acima } \\
\text { mencionados; } \\
\text { Nota-se que nestes processos de tempo e temperatura elevados não há a necessidade de monitorar vírus entéricos e ovos de } \\
\text { helmintos. Estes regimes de tempo e temperatura comprovaram através de pesquisas extensivas a eficiência na remoção destes } \\
\text { patógenos. }\end{array}$} \\
\hline Alternativas & \multicolumn{4}{|c|}{ Requisitos } \\
\hline $\begin{array}{l}\text { Alternativa 2: } \\
\text { Lodo Tratado Em } \\
\text { Processos com pH e } \\
\text { Temperatura Elevados. }\end{array}$ & \multicolumn{4}{|c|}{$\begin{array}{l}\text { Elevação do pH para valores acima de } 12 \text { por pelo menos } 72 \text { horas; } \\
\text { Manutenção da Temperatura acima de } 50^{\circ} \mathrm{C} \text { por pelo menos } 12 \text { horas durante o período que o pH estiver acima de 12; } \\
\text { Secagem do lodo ao ar para valores acima de } 50 \% \text { de TS, após o período de } 72 \text { horas; } \\
\text { Atendimento dos Requisitos de Coliformes Termotolerantes ou Salmonella sp. (Ver Tabela 4) para todos os regimes acima } \\
\text { mencionados. } \\
\text { Nota-se que nestes processos de pH e temperatura elevados não há a necessidade de monitorar vírus entéricos e ovos viáveis de } \\
\text { helmintos. Estes regimes de tempo e temperatura comprovaram através de pesquisas extensivas a eficiência na remoção destes } \\
\text { patógenos. }\end{array}$} \\
\hline $\begin{array}{l}\text { Alternativa 3: } \\
\text { Lodo Tratado Em } \\
\text { Outros Processos } \\
\text { Conhecidos. }\end{array}$ & \multicolumn{4}{|c|}{$\begin{array}{l}\text { Aplicável a processos listados nas alternativas } 1 \text { e 2, mas que não atenderam os requisitos operacionais destas alternativas; } \\
\text { Deverá ser realizado monitoramento abrangente de vírus entéricos e ovos viáveis de helmintos durante cada período de } \\
\text { monitoramento (em função dos parâmetros de operação utilizados), até que seja demonstrado que o processo atingiu níveis } \\
\text { adequados de redução destes patógenos. A fim de comprovar a eficiência do processo, a presença de vírus entéricos e ovos viáveis } \\
\text { de helmintos deve ser comprovada no lodo a ser tratado; } \\
\text { O monitoramento para detecção de ovos de helmintos e vírus entéricos no lodo a ser tratado deve ocorrer em um período de no } \\
\text { mínimo } 4 \text { semanas (para ovos viáveis de helmintos) e de } 2 \text { semanas para vírus entéricos; } \\
\text { Comprovada a presença de vírus entéricos no lodo a ser tratado, a sua presença no lodo tratado deverá ser menor que } 1 \text { UFP } \\
\text { (Unidade Formadora de Placa) por } 4 \text { gramas de sólidos totais (base seca); } \\
\text { Adicionalmente, a densidade de ovos de helmintos no lodo tratado deverá ser menor que } 1 \text { ovo por } 4 \text { gramas de sólidos totais (base } \\
\text { seca); } \\
\text { Após atendidos os níveis de patógenos mencionados nos itens anteriores, o intervalo de cada parâmetro operacional deve ser } \\
\text { registrado, de forma que o processo passe a operar nestes intervalos. O posterior monitoramento de vírus entéricos e ovos viáveis } \\
\text { de helmintos não mais será necessário; } \\
\text { Atendimento dos Requisitos de Coliformes Termotolerantes ou Salmonella sp. (Ver Tabela 4). }\end{array}$} \\
\hline $\begin{array}{l}\text { Alternativa 4: } \\
\text { Lodo Tratado } \\
\text { Em Processos } \\
\text { Desconhecidos. }\end{array}$ & \multicolumn{4}{|c|}{$\begin{array}{l}\text { Caracterização do lodo para Salmonella sp., vírus entéricos e ovos viáveis de helmintos em um dos seguintes momentos: } \\
\text { Quando o lodo ou material derivado for utilizado ou disposto; } \\
\text { Quando o lodo for preparado para venda ou doação em sacos ou outros recipientes para aplicação no solo; } \\
\text { Quanto o lodo for preparado para atender aos padrões de Excelente Qualidade - EQ (em termos de metais pesados) } \\
\text { A densidade de vírus entéricos no lodo tratado por processo enquadrado nesta alternativa deverá ser menor que } 1 \text { UFP (Unidade } \\
\text { Formadora de Placa) por } 4 \text { gramas de sólidos totais (base seca); } \\
\text { A densidade de ovos viáveis de helmintos no lodo tratado deverá ser menor que } 1 \text { ovo por } 4 \text { gramas de sólidos totais (base seca); } \\
\text { Atendimento dos Requisitos de Coliformes Termotolerantes e Salmonella sp. (Ver Tabela 4); } \\
\text { Necessidade de análise de cada lote de lodo a ser utilizado ou disposto no solo com relação aos patógenos mencionados, mesmo } \\
\text { que fique demonstrada a eficiência do processo na sua redução. }\end{array}$} \\
\hline $\begin{array}{l}\text { Alternativa 5: } \\
\text { Lodo Tratado Em } \\
\text { Um Processo de } \\
\text { Redução Adicional de } \\
\text { Patógenos. }\end{array}$ & \multicolumn{4}{|c|}{$\begin{array}{l}\text { O lodo tratado em um dos Processos de Redução Adicional de Patógenos deverá atender aos critérios listados na Tabela } 3 \text { de } \\
\text { acordo com o processo adotado. A operação do processo de acordo com os parâmetros operacionais listados para cada processo } \\
\text { neste quadro dispensa o monitoramento do lodo tratado para vírus entéricos e ovos viáveis de helmintos; } \\
\text { Atendimento dos Requisitos de Coliformes Termotolerantes ou Salmonella sp. (Ver Tabela 4). }\end{array}$} \\
\hline $\begin{array}{l}\text { Alternativa 6: } \\
\text { Lodo Tratado Em Um } \\
\text { Processo Equivalente } \\
\text { a Um Processo de } \\
\text { Redução Adicional de } \\
\text { Patógenos. }\end{array}$ & \multicolumn{4}{|c|}{$\begin{array}{l}\text { O lodo é tratado por um outro processo reconhecido pela autoridade ambiental como um Processo de Redução Adicional de } \\
\text { Patógenos; } \\
\text { O processo de tratamento deverá remover patógenos a níveis compatíveis com um dos Processos de Redução Adicional de } \\
\text { Patógenos listados na Tabela 3; } \\
\text { Atendimento dos Requisitos de Coliformes Termotolerantes ou Salmonella sp. (Ver Tabela 4). }\end{array}$} \\
\hline
\end{tabular}


Apenas uma categoria de processos de higienização do lodo da Norma 503 foi reproduzida na regulamentação brasileira $\mathrm{RC} \mathrm{n}^{\circ}$ 375/2006. Esta categoria de processos se refere à alternativa 5 de higienização do lodo, e estão ilustradas na tabela 3 a seguir.

Tabela 3 - Processos de Redução Adicional de Patógenos.

A. Compostagem confinada ou em leiras aeradas $\left(3\right.$ dias a $55^{\circ} \mathrm{C}$ no mínimo) ou com revolvimento das leiras $\left(15\right.$ dias a $55^{\circ} \mathrm{C}$ no mínimo, com revolvimento mecânico da leira durante pelo menos 5 dias ao longo dos 15 do processo).

B. Secagem térmica direta ou indireta para reduzir a umidade do lodo de esgoto ou produto derivado a $10 \%$ ou menos, devendo a temperatura das partículas de lodo de esgoto ou produto derivado superar $80^{\circ} \mathrm{C}$ ou a temperatura de bulbo úmido de gás, em contato com o lodo de esgoto ou produto derivado no momento da descarga do secador, ser superior a $80^{\circ} \mathrm{C}$.

C. Tratamento térmico pelo aquecimento do lodo de esgoto ou produto derivado líquido a $180^{\circ} \mathrm{C}$, no mínimo, durante um período de 30 minutos.

D. Digestão aeróbia termofílica a ar ou oxigênio, com tempo de residência de 10 dias a temperaturas de 55 a $60^{\circ} \mathrm{C}$.

E. Processos de irradiação com raios beta a dosagens mínimas de 1 megarad a $20^{\circ} \mathrm{C}$, ou com raios gama na mesma intensidade e temperatura, a partir de isótopos de Cobalto 60 ou Césio 137

F. Processos de pasteurização, pela manutenção do lodo de esgoto ou produto derivado a uma temperatura mínima de $70^{\circ} \mathrm{C}$, por um período de pelo menos 30 minutos.

Fonte: Estados Unidos, 1994a

Para cada uma das seis alternativas de higienização do lodo de esgoto apresentadas na Tabela 2 para produção de Lodo Classe A, o lodo tratado deve, de acordo com a Norma 503, ser caracterizado em função dos seguintes organismos patogênicos: coliformes termotolerantes ou Salmonella sp. Ou seja, para cada lote de lodo disponibilizado para uso ou comercialização, deve ser quantificado um desses microrganismos. Quando há desconformidade para um deles, avalia-se o outro. Em suma, o lodo processado em uma das seis alternativas apresentadas na Tabela 2 é considerado Classe $A$ se atendido aos respectivos critérios operacionais da alternativa de higienização utilizada, e aos seguintes critérios apresentados na Tabela 4, a seguir.
Tabela 4 - Requisitos de Patógenos para as Seis Alternativas.

Critérios:

A densidade de Coliformes Termotolerantes deverá ser inferior a 1000 NMP / g de sólidos totais em base seca, ou:

A densidade de Salmonella sp. deverá ser menos que $3 \mathrm{NMP} / 4 \mathrm{~g}$ de sólidos totais em base seca.

OBS.: Qualquer um destes requisitos de patógenos deverá se atendido em pelo menos um dos seguintes momentos:

Quando o lodo tratado for utilizado ou disponibilizado para uso; Quando o lodo tratado for preparado para venda ou doação em sacos ou outros recipientes para aplicação no solo;

Ouando o lodo tratado ou produto derivado for preparado para avaliação dos requisitos de excelente qualidade.

Fonte: Estados Unidos, 1994a Requisitos de Patógenos

Cabe realçar, dentre estas alternativas da tabela 2, a alternativa 1 de tratamento térmico de lodo de ETE. A utilização de parâmetros de controle operacional como indicador de qualidade microbiológica para alternativas conhecidas de tratamento do lodo como tempo e temperatura foi obtida nos EUA após extensas pesquisas, onde evidências experimentais demonstraram que regimes controlados de tempo e temperatura reduziam os níveis de patógenos para concentrações abaixo dos limites de detecção da época, conforme Estados Unidos (2003). Outra nota interessante a se destacar é que, segundo Estados Unidos (2003), através desta abordagem evita-se o dispêndio de tempo e de dinheiro com análises, geralmente bastante caras, para a detecção de agentes patogênicos específicos.

$\mathrm{O}$ atendimento aos requisitos operacionais das alternativas de higienização da Tabela 2 da Norma 503 não significa a mesma equivalência de densidade de patógenos estabelecida pelo MAPA, já que os requisitos de patógenos desta instituição são mais restritivos que os da EPA. Portanto, pode ser necessário um ajuste destes parâmetros operacionais das alternativas de tratamento de produção de lodo Classe A, principalmente para atender ao critério de ausência de Salmonella sp. em $10 \mathrm{~g}$ de base seca de lodo. 


\section{ATRATIVIDADE A VETORES}

$O$ lodo de esgoto, mesmo higienizado, pode ainda apresentar atratividade a vetores e, com isso, ser "recontaminado" por patógenos. De acordo com a RC no 375/2006, a atratividade a vetores é a característica que o lodo de esgoto apresenta de atrair insetos, roedores e outros vetores de agentes patogênicos. Ou seja, a redução da sua atratividade a vetores é medida fundamental para evitar a "recontaminação" do lodo higienizado por microrganismos patogênicos. Estando estabilizado, o lodo não mais apresentará potencial de geração de odores, mesmo quando reumidificado, e o risco de ser "recontaminado" será bastante re- duzido. Esta preocupação não se faz presente em nenhum dos dispositivos legais do MAPA.

De acordo com Estados Unidos (2003), a questão de recrescimento é algo restrito a certas bactérias patogênicas. Vírus, helmintos e protozoários não são capazes de recrescimento fora do organismo hospedeiro específico. E uma vez reduzidos através de tratamento, suas populações não crescem mais.

\section{A Tabela 5 apresenta os processos e os respectivos critérios para redução da atratividade a vetores do lodo de esgoto que podem ser aplicados durante ou após um processo de redução de patógenos.}

Tabela 5 - Critérios para redução da atratividade a vetores do lodo de esgoto.

\begin{tabular}{|c|c|}
\hline Processo & Critérios* \\
\hline $\begin{array}{l}\text { A - Digestão } \\
\text { anaeróbia do lodo de } \\
\text { esgoto ou produto } \\
\text { derivado. }\end{array}$ & $\begin{array}{l}1 \text { - A concentração de sólidos voláteis (SV) deve ser reduzida em } 38 \% \text { ou mais. A redução de SV é medida pela comparação de sua } \\
\text { concentração no afluente, do processo de estabilização de lodo de esgoto ou produto derivado (digestão aeróbia ou anaeróbia), } \\
\text { com a sua concentração no lodo de esgoto ou produto derivado pronto para uso ou disposição. } \\
\text { ou, } \\
\mathbf{2} \text { - Caso a redução de } 38 \% \text { de SV do lodo de esgoto ou produto derivado não seja atingida, após o mesmo ser submetido a um } \\
\text { processo de digestão anaeróbia, o processo adotado será aceito apenas se em escala de laboratório a mesma amostra de lodo } \\
\text { de esgoto ou produto derivado, após um período adicional de } 40 \text { dias de digestão, com temperatura variando entre } 30 \text { e } 37^{\circ} \mathrm{C} \text {, } \\
\text { apresentar uma redução de SV menor que } 17 \% \text {. }\end{array}$ \\
\hline $\begin{array}{l}\text { B - Digestão aeróbia } \\
\text { do lodo de esgoto ou } \\
\text { produto derivado. }\end{array}$ & $\begin{array}{l}1 \text { - A concentração de sólidos voláteis (SV) deve ser reduzida em } 38 \% \text { ou mais. A redução de SV é medida pela comparação de sua } \\
\text { concentração no afluente, do processo de estabilização de lodo de esgoto ou produto derivado (digestão aeróbia ou anaeróbia), } \\
\text { com a sua concentração no lodo de esgoto ou produto derivado pronto para uso ou disposição. } \\
\text { ou, } \\
3 \text { - Caso a redução de } 38 \% \text { de SV do lodo de esgoto ou produto derivado não seja atingida, após o mesmo ser submetido a um } \\
\text { processo de digestão aeróbia, e o lodo de esgoto ou produto derivado possuir uma concentração de matéria seca (MS) inferior a } 2 \% \text {, } \\
\text { o processo adotado será aceito apenas se em escala de laboratório a mesma amostra de lodo de esgoto ou produto derivado, após } \\
\text { um período adicional de } 30 \text { dias de digestão, com temperatura mínima de } 20^{\circ} \mathrm{C} \text {, apresentar uma redução de } \mathrm{SV} \text { menor que } 15 \% \text {. } \\
\text { ou, } \\
\mathbf{4} \text { - Após o período de digestão, a taxa específica de consumo de oxigênio (SOUR - Specific Oxygen Uptake Rate) deve ser menor ou } \\
\text { igual a } 1,5 \text { mg } \mathrm{O}_{2} \text { /[hora x grama de sólidos totais (ST)] a } 20^{\circ} \mathrm{C} \text {. } \\
\text { ou, } \\
5 \text { - Relacionado à compostagem ou outro processo aeróbio: durante o processo, a temperatura deve ser mantida acima de } 40^{\circ} \mathrm{C} \text { por } \\
\text { pelo menos } 14 \text { dias. A temperatura média durante este período deve ser maior que } 45^{\circ} \mathrm{C} \text {. }\end{array}$ \\
\hline C-Compostagem. & $\begin{array}{l}5 \text { - Relacionado à compostagem ou outro processo aeróbio: durante o processo, a temperatura deve ser mantida acima de } 40^{\circ} \mathrm{C} \text { por } \\
\text { pelo menos } 14 \text { dias. A temperatura média durante este período deve ser maior que } 45^{\circ} \mathrm{C} \text {. }\end{array}$ \\
\hline $\begin{array}{l}\text { D - Estabilização } \\
\text { química. }\end{array}$ & $\begin{array}{l}\text { 6- A uma temperatura de } 25^{\circ} \mathrm{C} \text {, a quantidade de álcali misturada c } \\
\text { para que o pH seja elevado até pelo menos } 12 \text { por um período míni } \\
\text { Estes valores devem ser alcançados sem que seja feita uma aplicaç }\end{array}$ \\
\hline & $\begin{array}{l}7 \text { - Relacionado à secagem com ventilação forçada ou térmica para lodos de esgoto ou produto derivado que não receberam adição } \\
\text { de lodos primários brutos: após o processo de secagem, a concentração de sólidos deve alcançar no mínimo } 75 \% \text { MS, sem que haja } \\
\text { mistura de qualquer aditivo. Não é aceita a mistura com outros materiais para alcançar a porcentagem exigida de sólidos totais. } \\
\text { ou, } \\
\mathbf{8} \text { - Relacionado à secagem por aquecimento ou ao ar para lodos de esgoto ou produto derivado que receberam adição de lodos } \\
\text { primários brutos: após o processo de secagem, a concentração de sólidos deve alcançar no mínimo } 90 \% \text { MS, sem que haja mistura } \\
\text { de qualquer aditivo. Não se aceita a mistura com outros materiais para alcançar a porcentagem exigida de sólidos totais. }\end{array}$ \\
\hline $\begin{array}{l}\text { F- Aplicação } \\
\text { subsuperficial**;: }\end{array}$ & $\begin{array}{l}9 \text { - Relacionado à aplicação do lodo de esgoto ou produto derivado no solo na forma líquida: a injeção do lodo de esgoto ou produto } \\
\text { derivado líquido sob a superfície será aceita como um processo de redução de atração de vetores se: não for verificada a presença } \\
\text { de quantidade significativa de lodo de esgoto ou produto derivado na superfície do solo após uma hora da aplicação. No caso de } \\
\text { lodo de esgoto ou produto derivado classe A, a injeção do lodo de esgoto ou produto derivado deve ser feita num período máximo } \\
\text { de até oito horas após a finalização do processo de redução de patógenos. }\end{array}$ \\
\hline $\begin{array}{l}\text { G - Incorporação r } \\
\text { Solo***;. }\end{array}$ & $\begin{array}{l}10 \text { - Relacionado à aplicação do lodo de esgoto ou produto derivado no solo: nesta situação, o lodo de esgoto ou produto derivado } \\
\text { deve ser incorporado no solo antes que transcorram seis horas após a aplicação na área. Se o lodo de esgoto ou produto derivado } \\
\text { for classe A, deve ser aplicado e incorporado decorridos, no máximo, oito horas após sua descarga do processo de redução de } \\
\text { patógenos. }\end{array}$ \\
\hline
\end{tabular}


Os processos listados na Tabela 5 de 'A' a 'E' com seus respectivos critérios podem ser empregados na própria ETE ou em um local específico para gerenciamento dos lodos de ETEs. Já os processos $F$ e $G$ são processos para redução da atratividade a vetores aplicáveis diretamente no campo agrícola.

De forma a ilustrar a importância da redução da atratividade a vetores, a Norma 503 prevê a possibilidade de se ter um Lodo Classe A, porém sem se ter conseguido atingir a redução à atratividade por outros meios. De acordo com Estados Unidos (1994a), nestes casos especiais, a redução da atratividade é conseguida através da injeção do lodo no solo. Nestas situações, caso as bactérias patogênicas estejam presentes (sobreviventes ou introduzidas por contaminação), seu número cresce lentamente após 8 horas do processamento, mas cresce rapidamente após este período. Este crescimento explosivo não ocorre no lodo Classe $B$, pois a alta densidade de bactérias não patogênicas inibe o crescimento das patogênicas. Além disso, a utilização de lodo classe B exige uma série de restrições, que reduz a exposição pública aos patógenos, não sendo necessária esta requisição especial ao lodo Classe B. Nota-se a seriedade desta instituição no controle da patogenicidade, onde um lodo que foi submetido a um processo de higienização compatível como Lodo Classe A, portanto, mais rigoroso que um processo que gera Lodo Classe B, e que não passou por um dos cinco primeiros critérios de redução da atratividade a vetores da Tabela 5, necessita deste cuidado especial.
Apesar do MAPA não fazer qualquer consideração em relação ao atendimento dos requisitos de Redução de Atratividade a Vetores, entendemos que deva ser realizada esta verificação por parte dos responsáveis pela ETE, de modo a se criar mais uma barreira de segurança na preservação sanitária e ambiental referente à disposição de produto agrícola contendo lodo de esgoto em sua composição.

\section{METAIS PESADOS}

O MAPA não estabelece restrições para taxas máximas de aplicação de fertilizante orgânico ou condicionador de solo Classe $D$ na agricultura, nem requisitos quanto ao monitoramento de contaminantes no solo em função da presença de metais pesados nestes produtos. Estabelece, porém, que seja mantido pelos estabelecimentos controle da destinação destes produtos à disposição da fiscalização pelo prazo mínimo de 180 (cento e oitenta) dias.

A instrução normativa - IN MAPA no 27/2006 (Brasil, 2006a) apresenta os limites máximos de contaminantes, incluindo os metais pesados. Já a Norma 503 apresenta os níveis máximos de metais pesados no lodo, os limites anuais de aplicação e os limites cumulativos desses metais pesados no solo, fundamentada na metodologia das vias de risco e após checar as rotas mais críticas.

A Tabela 6 a seguir apresenta a lista de metais pesados estabelecidos pelo MAPA, comparados com os limites apresentados para metais pesados na Norma 503 e RC n³75/2006. 
Tabela 6 - Concentrações Máximas de Metais Pesados conforme o Enfoque das Diferentes Instituições

\begin{tabular}{|c|c|c|c|c|c|}
\hline \multirow{3}{*}{ Metal Pesado } & \multicolumn{3}{|c|}{ Regulamentações Ambientais } & \multicolumn{2}{|c|}{ IN MAPA n 27/2006 (Brasil, 2006a) } \\
\hline & \multicolumn{2}{|c|}{ Norma 503 (Estados Unidos, 1993) } & \multirow{2}{*}{$\begin{array}{c}\mathrm{RC} \mathrm{n}^{0} 375 / 2006 \\
\text { (Brasil, 2006d) } \\
\text { (mg/kg) }\end{array}$} & \multirow{2}{*}{$\begin{array}{c}\text { Fert. Org. Classe D } \\
(\mathrm{mg} / \mathrm{kg})\end{array}$} & \multirow{2}{*}{$\begin{array}{c}\text { Cond. Solo Classe D } \\
(\mathrm{mg} / \mathrm{kg})\end{array}$} \\
\hline & Valores máximos $(\mathrm{mg} / \mathrm{kg})^{(1)}$ & $\begin{array}{c}\text { Lodo } \mathrm{EQ}^{(2)} \text { ou } \mathrm{PC}^{(3)} \\
(\mathrm{mg} / \mathrm{kg})\end{array}$ & & & \\
\hline Arsênio & 75 & 41 & 41 & 20,00 & 20,00 \\
\hline Bário & - & - & 1300 & - & - \\
\hline Cádmio & 85 & 39 & 39 & 3,00 & 8,00 \\
\hline Chumbo & 840 & 300 & 300 & 150,00 & 300,00 \\
\hline Cobre & 4300 & 1500 & 1500 & - & - \\
\hline Cromo & 3000 & 1200 & 1000 & 200,00 & 500,00 \\
\hline Mercúrio & 57 & 17 & 17 & 1,00 & 2,50 \\
\hline Níquel & 420 & 420 & 420 & 70,00 & 175,00 \\
\hline Selênio & 100 & 36 & 100 & 80,00 & 80,00 \\
\hline Zinco & 7500 & 2800 & 2800 & - & - \\
\hline Molibdênio & 75 & - & 50 & - & - \\
\hline
\end{tabular}

(1) Base seca.

(2) EQ - Lodo Classe A que atende ao padrão mais restritivo de metais da Norma 503.

(3) PC - Lodo Classe B que atende ao padrão mais restritivo de metais da Norma 503.

As concentrações de metais pesados apresentadas na Tabela 6 demonstram que o padrão de qualidade do MAPA para os produtos agrícolas é mais rígido que o padrão de qualidade regulamentado pelas instituições ambientais. Para a maioria dos metais, o padrão de qualidade não ultrapassa $50 \%$ do padrão de qualidade para Lodo EQ - Exceptional Quality/Qualidade Excepcional, ou PC Pollutant Concentration/Concentração Limite de Poluente, conforme classificação dada pela Norma 503. Essas classificações da Norma 503 para lodo de esgoto em função de metais pesados se referem ao lodo que atende a padrões mais restritivos de metais pesados e que foi submetido a processo de higienização compatível com a produção de lodo classe A e lodo classe B. Ou seja, Lodo EQ se refere ao lodo Classe $A$ que atende ao padrão mais restritivo de metais. Lodo PC é o lodo que também atende ao padrão mais restritivo de metais, porém, que foi submetido a um processo de higienização do lodo do tipo classe B. É importante frisar que nos EUA a EPA não exige o monitoramento de metais pesados no solo agrícola para as áreas que recebem exclusivamente aplicação de lodo de esgoto do tipo EQ ou PC, em função das baixas concentrações de metais nestes resíduos. Como também não há uma exigência de monitoramento de metais no solo nas instruções normativas do MAPA, esta rotina operacional fica descartada sem ferir a legislação, sendo este fator outra vantagem da abordagem de produto por uma companhia de saneamento.

Outra observação da Tabela 6 é que alguns metais são mencionados pelas instituições ambientais como poluentes, enquanto que para o MAPA são classificados como macronutrientes secundários ou micronutrientes (Brasil, 2009). Enquadram-se nesta condição o cobre, o zinco e o molibdênio. Já o níquel, apesar de ser também considerado como micronutriente de planta, é também listado como contaminante, estando limitado no fertilizante orgânico Classe $\mathrm{D}$ e condicionador de solo Classe D a $70 \mathrm{mg} / \mathrm{kg}$ de produto, e $175 \mathrm{mg} / \mathrm{kg}$ de produto, respectivamente. Assim, é recomendável adotar para os metais cobre, zinco e o molibdênio, não abordados pelo MAPA como contaminantes, o padrão de referência da Norma 503 para Lodo de Excepcional Qualidade.

Quanto a aspectos de comercialização e uso do lodo no solo, a Norma 503 admite o uso agrícola sem restrições quando o lodo de esgoto apresenta 
padrão de qualidade Classe A (em termos de patógenos) e concentração de metais pesados abaixo do padrão considerado como de excepcional qualidade, podendo ser, inclusive, comercializado ensacado e sem restrições para uso. No entanto este tipo de comercialização 'sem restrições para uso' não pode ser utilizado caso seja adotada a abordagem de produto do MAPA, independente do produto ser comercializado a granel ou ensacado, devido às restrições de manuseio e aplicação a certas culturas agrícolas citadas neste artigo.

Vale lembrar que na $\mathrm{RC} n^{0} 375 / 2006$ não foi prevista a classificação do lodo em função da concentração de metais pesados. Assim, mesmo que o lodo de esgoto apresente características de excepcional qualidade, há na regulamentação ambiental brasileira uma série de restrições ao uso, tais como o monitoramento da fertilidade do solo antes de cada aplicação e a cada três anos, o monitoramento de substâncias inorgânicas (metais pesados) no solo, o monitoramento de substâncias orgânicas sempre que for identificada sua presença no produto derivado de lodo de esgoto, além do monitoramento das águas subterrâneas e superficiais quando solicitadas pelo órgão ambiental competente, o que torna o controle operacional da aplicação de lodo no solo agrícola pela via de resíduo bastante complexo, principalmente paras as ETEs de pequeno porte.

\section{VERIFICAÇÃO DO ATENDIMENTO AOS REQUISITOS AGRONÔMICOS}

Conforme discutido neste artigo, o padrão de qualidade para produto agrícola do MAPA envolve $o$ atendimento de três classes de parâmetros: densidade de patógenos, metais pesados (ou substâncias inorgânicas) e parâmetros de interesse agronômico.

Para o atendimento dos limites de patógenos, apresentamos como base as tecnologias de tratamento (higienização do lodo) da Norma 503, que, associada aos critérios de redução da atratividade a vetores do lodo, poderão garantir o padrão de qualidade microbiológica do MAPA. Contudo, é importante destacar que, na abordagem de produto, o atendimento aos padrões microbiológicos e de substâncias inorgânicas não garante por si só o registro do material como produto agrícola, devido aos requisitos agronômicos apresentados na Tabela 1. A tecnologia de tratamento do lodo selecionada para a redução de patógenos poderá comprometer a composição de nutrientes do produto final, podendo acarretar em alguns casos a necessidade de emprego de nova matéria-prima para adequação do produto final.

Para fins de exemplificação, o emprego da alternativa 2 de higienização apresentada na Tabela 2 , que envolve processos com elevação de $\mathrm{pH}$ e temperatura durante um período determinado, provavelmente atenderá aos requisitos de patógenos, mas poderá acarretar volatilização de algum nutriente, além de alterar a concentração dos demais nutrientes pelo aporte de sólidos ao produto, no caso de elevação do $\mathrm{pH}$ através da aplicação de cal, por exemplo. Nesta situação particular, a volatilização de nitrogênio provocada pela elevação do $\mathrm{pH}$ poderá tornar o produto final com concentração deste nutriente abaixo do mínimo permitido, além de elevar em demasia a sua relação $\mathrm{C} / \mathrm{N}$, e podendo, com isso, inviabilizar seu registro no MAPA. Em testes preliminares com processo patenteado de pasteurização alcalina através da introdução de cal com o lodo de ETE na SABESP, devidamente reconhecida pela agência ambiental USEPA com equivalência de Processo de Redução Adicional de Patógenos, verificou-se que o produto resultante não atendia ao requisito do MAPA no que diz respeito à relação $\mathrm{C} / \mathrm{N}$. Outros processos de higienização do lodo, como a compostagem, deverão ser dimensionados para que atendam à temperatura ideal para desinfecção, mas que também atendam no produto final ao teor mínimo de nutrientes e à relação máxima de $\mathrm{C} / \mathrm{N}$. O dimensionamento da quantidade de material estruturante necessário para o processo deverá avaliar estes dois fatores simultaneamente. 
Ainda com relação ao processo de compostagem, outra observação interessante a ser comentada diz respeito ao foco da Norma 503, direcionada essencialmente para a higienização do lodo. Por exemplo, as condições operacionais para a produção de Lodo Classe A através de compostagem em leiras revolvidas são: temperatura do lodo mantida a $55^{\circ} \mathrm{C}$ ou mais durante 15 dias ou mais. Esta fase de processo da compostagem refere-se à fase de decomposição e é onde ocorre a fermentação termofílica, conforme Chiumenti (2005). A fase subsequente da compostagem é a fase de maturação, conhecida como fase mesofílica e normalmente dura semanas.

Tanto o MAPA quanto a Norma 503 não apresentam considerações referentes à maturação de um lodo compostado, no entanto, esta é uma preocupação presente em outros dispositivos, como por exemplo, na Norma Francesa NF U 44-095 (França, 2002), que abrange a compostagem com lodo de ETE. Esta Norma traz o Índice de Estabilidade Biológica do Composto como parâmetro de controle. Para caracterizar esta estabilidade biológica, Chiumenti (2005) cita como parâmetro-chave o Índice de Respiração e o Índice de Humificação. $O$ índice de respiração representa a quantidade de oxigênio consumida pelo substrato orgânico, e é inversamente proporcional à estabilidade biológica do material. Já o índice de humificação representa o grau de mineralização do composto, representado pela formação e acumulação de substâncias húmicas e decréscimo da fração orgânica instável do material compostado.

De acordo com a California Compost Quality Council (2001), um produto da compostagem não maturado e com deficiência de estabilização pode apresentar diversos problemas na estocagem, comercialização e uso. $\mathrm{Na}$ estocagem estes materiais podem apresentar bolsões anaeróbios que podem levar à produção de maus odores, incêndios e/ou desenvolvimento de compostos tóxicos. A decomposição contínua e ativa destes materiais quando dispostos no solo ou adicionados a meios de cultura podem trazer impactos negativos no crescimento da planta devido à redução de oxigênio e/ou nitrogênio disponível ou, inclusive, pela presença de compostos fitotóxicos.

Se, por um lado, a Norma 503 não faz menção a parâmetros de estabilidade biológica para lodo compostado, em virtude do seu foco voltado exclusivamente à proteção ambiental e da saúde pública, por outro lado, esperava-se que a instituição voltada à proteção da produtividade agrícola, neste caso, o MAPA, apresentasse de forma explícita mecanismos de controle do grau de estabilidade biológica dos produtos contendo lodo de esgoto.

\section{COMENTÁRIOS E CONCLUSÕES}

O processo de registro de lodo de esgoto junto ao MAPA, visando ao seu uso benéfico como produto agrícola na função de fertilizante ou condicionador de solo, é uma prática que vem sendo utilizada por algumas companhias de saneamento no país. Apesar da aparente menor complexidade para aplicação agrícola via produto, já que o MAPA não faz qualquer menção aos processos de higienização e estabilização do lodo, o padrão de qualidade microbiológica e de substâncias inorgânicas para produto contendo lodo de esgoto é, de forma geral, mais restritivo do que os padrões estabelecidos nos textos normativos das instituições ambientais, brasileira e americana.

Entendemos que os dispositivos do MAPA apresentam as condições necessárias, mas não suficientes, para assegurar a proteção de saúde pública e ambiental, já que não há referências a medidas de higienização do lodo, bem como de redução da sua atratividade a vetores apresentadas e discutidas neste artigo. Apesar de não obrigatório, entendemos que os geradores de produto derivado de lodo de ETE devem atender a estes requisitos de forma voluntária. 
Por outro lado, o trâmite de uso agrícola do lodo de ETE como resíduo, através da manifestação da agência ambiental com base na RC n³75/2006, mostra-se tão restritivo que afasta as companhias de saneamento a percorrerem esta trajetória. De caso prático, conhece-se como adeptos desta prática apenas a SANEPAR, no Estado do Paraná. Contudo, não se sabe até que ponto os dados gerados com o monitoramento das áreas de aplicação de lodo nesse Estado vêm contribuindo para o aumento do conhecimento científico, através da análise crítica pela academia ou pelas agências ambientais que compuseram a câmara técnica para elaboração da referida resolução CONAMA, e cujo argumento na época para tais monitoramentos era de que gerariam dados que preencheriam esta lacuna do conhecimento.

Como a qualidade analítica do produto agrícola contendo lodo de ETE é aferida com frequência espaçada no tempo, onde lotes de produto disponibilizado para uso agrícola entre os intervalos de aferição analítica podem apresentar volumes consideráveis, é fundamental controlar as variáveis de processo, de forma a garantir a uniformidade da qualidade do produto. Como - MAPA não faz consideração sobre o controle operacional do processo de higienização do lodo, este artigo procurou preencher esta lacuna através dos requisitos estabelecidos pela EPA para controle do processo de higienização, órgão de controle ambiental americano com vasta experiência no assunto.

O uso agrícola do lodo é medida que vai ao encontro dos objetivos da Política Nacional dos Resíduos Sólidos, principalmente quanto ao reaproveitamento de resíduos e seu uso benéfico. Contudo, o principal benefício desta prática é permitir que a matéria orgânica e os nutrientes presentes no lodo de esgoto, especialmente o nitrogênio e o fósforo, possam ser reciclados no solo, reduzindo a demanda da produção agrícola por fertilizantes sintéticos.
A apresentação detalhada dos procedimentos administrativos, tais como a relação de documentos do estabelecimento, requisitos do controle de qualidade, análises periciais e ações de fiscalização do MAPA para aferição da qualidade dos produtos, poderá ser consultada diretamente nos regulamentos do MAPA mencionados neste artigo.

\section{REFERÊNCIAS BIBLIOGRÁFICAS}

BASTOS, Rafael K. X.; BEVILACQUA, Paula D.; MARA, Davi D. Análise crítico-comparativa das regulamentações brasileira, estadunidense e britânica de qualidade microbiológica de biossólidos para uso agrícola. Revista DAE. Edição nº 191. 2013.

BRASIL. Lei Federal nº 6.894, de 16 de dezembro de 1980. Dispõe sobre a inspeção e fiscalização da produção e do comércio de fertilizantes, corretivos, inoculantes, estimulantes ou biofertilizantes, destinados à agricultura, e dá outras providências. Poder Executivo: Brasília, DF, 1980.

BRASIL. Decreto Federal $n^{\circ} 4.954$, de 14 de janeiro de 2004. Aprova o Regulamento da Lei $n^{\circ} 6.894$, de 16 de dezembro de 1980 , que dispõe sobre a inspeção e fiscalização da produção e do comércio de fertilizantes, corretivos, inoculantes ou biofertilizantes destinados à agricultura, e dá outras providências. Poder Executivo, Brasília, DF. 2004.

BRASIL. Instrução Normativa n 27, de 5 de junho de 2006. Estabelece os limites máximos de contaminantes e agentes fitotóxicos patogênicos ao homem, animais e plantas a serem atendidos nos fertilizantes, corretivos, inoculantes e biofertilizantes. Ministério da Agricultura, Pecuária e Abastecimento. Poder Executivo, Brasília, DF. 2006ª

BRASIL. Instrução Normativa n 35 , de 4 de julho de 2006. Estabelece as normas sobre especificações em tolerâncias, registro, embalagem e rotulagem dos corretivos de acidez, de alcalinidade e de sodicidade e dos condicionadores de solo, destinados à agricultura. Ministério da Agricultura, Pecuária e Abastecimento. Poder Executivo, Brasília, DF. 2006b.

BRASIL. Resolução CONAMA n 375, de 29 de agosto de 2006. Define critérios e procedimentos, para o uso agrícola de lodos de esgoto gerados em estações de tratamento de esgoto sanitário e seus produtos derivados, e dá outras providências. Ministério do Meio Ambiente. Poder Executivo, Brasília, DF. 2006c.

BRASIL. Resolução CONAMA n 380, de 31 de outubro de 2006. Retifica a Resolução CONAMA n 375/2006: Define critérios e procedimentos, para o uso agrícola de lodos de esgoto gerados em estações de tratamento de esgoto sanitário e seus produtos derivados, e dá outras providências. Ministério do Meio Ambiente. Poder Executivo, Brasília, DF. 2006d. 
BRASIL. Instrução Normativa nº 25, de 23 de julho de 2009. Estabelece as normas sobre as especificações e as garantias, as tolerâncias, o registro, a embalagem e a rotulagem dos fertilizantes orgânicos simples, mistos, compostos, organominerais e biofertilizantes destinados à agricultura. Ministério da Agricultura, Pecuária e Abastecimento. Poder Executivo, Brasília, DF. 2009.

BRASIL. Lei n 12.305, de 2 de agosto de 2010. Institui a Política Nacional de Resíduos Sólidos. Poder Executivo, Brasília, DF. 2010.

BRASIL. Decreto Federal n 8059, de 26 de julho de 2013. Altera o Anexo ao Decreto $n^{\circ} 4.954$, de 14 de janeiro de 2004, que aprova o Regulamento da Lei ${ }^{\circ} 6.894$, de 16 de dezembro de 1980 , que dispõe sobre a inspeção e fiscalização da produção e do comércio de fertilizantes, corretivos, inoculantes ou biofertilizantes destinados à agricultura. Poder Executivo, Brasília, DF. 2013a.

BRASIL. Instrução Normativa n ${ }^{53}$, de 23 de outubro de 2013. Estabelece diretrizes para registro de estabelecimentos e produtos. Ministério da Agricultura, Pecuária e Abastecimento. Poder Executivo, Brasília, DF. 2013b.

CALIFORNIA COMPOST QUALITY COUNCIL, 2001. Compost Maturity Index.

CARVALHO, P.C.T.; CARVALHO, F.J.P.C. Legislação de biossólidos. In. Biossólidos na Agricultura, Sabesp, 2001.

CHIUMENTI et al. Modern Composting Technologies, BioCycle, The JG Press, 2005.

CORREA, Rodrigo Studart; CORREA, Anelisa Studart. Valoração de Biossólidos como Fertilizantes e Condicionadores de Solo. Revista Sanare. Vol. 16. Ano 2001.

ESTADOS UNIDOS. EPA/625/R-92/013. Control of Pathogens and Vector Attraction in Sewage Sludge. USEPA. Poder Executivo, Washington, D.C. 2003.
ESTADOS UNIDOS. EPA/831/B-93/002a. Preparing Sewage Sludge for Land Application or Surface Disposal. USEPA. Poder Executivo, Washington, D.C. 1993.

ESTADOS UNIDOS. EPA/832/R-93/003. A Plain English Guide to The Part 503 Rule. USEPA. Poder Executivo, Washington, D.C. 1994a.

ESTADOS UNIDOS. EPA/831/B-93/002b. Land Application of Sewage Sludge. USEPA. Poder Executivo, Washington, D.C. 1994b.

ESTADOS UNIDOS. USEPA, CFR 40, Part 503. Standards for the use or disposal of sewage sludge. Poder Executivo, Washington, D.C. 1993.

FRANÇA. Norma Francesa NF U 44-095, de maio de 2002. Composts contenant des matières d'intérêt agronomique, issues du traitement des eaux. França, 2002.

SAMPAIO, Américo de Oliveira. Afinal, Queremos ou não Viabilizar o Uso Agrícola do Lodo Produzido em Estações de Esgoto Sanitário? Uma Avaliação Crítica da Resolução CONAMA 375. Revista DAE nº 193. Ano 2013.

SÃO PAULO (SP). Decisão de Diretoria da CETESB n 388/2010/P. Estabelece que qualquer material registrado no MAPA como Fertilizante independe de manifestação da CETESB para uso agrícola, já que são enquadrados como Produto Agronômico. Poder Executivo, São Paulo, , 2010.

TSUTIYA, Milton Tomoyuki et al. Características de Biossólidos Gerados em Estações de Tratamento de Esgotos. In: Biossólidos na Agricultura. Capítulo 4. 2001. 